\title{
Quantitative estimation of wastewater quality parameters by hyperspectral band screening using GC, VIP and SPA
}

\author{
Zheng Xing ${ }^{1,2}$, Junying Chen ${ }^{\text {Corresp., } 1,2}$, Xiao Zhao ${ }^{1,2}, \mathbf{Y u ~ L i ~}^{2}$, Xianwen $\mathbf{L i}^{2}$, Zhitao Zhang ${ }^{1,2}$, Congcong Lao ${ }^{2}$, Haifeng \\ Wang ${ }^{2}$ \\ ${ }^{1}$ Key Laboratory of Agricultural Soil and Water Engineering in Arid and Semiarid Areas, Ministry of Education, Northwest A\&F University, Yangling, \\ Shaanxi, China \\ ${ }^{2}$ College of Water Resources and Architectural Engineering, Northwest A\&F University, Yangling, Shaanxi, China
}

Corresponding Author: Junying Chen

Email address: cjyrose@126.com

Water pollution has been hindering the world's sustainable development. The accurate inversion of water quality parameters in sewage with visible-near infrared (VIS-NIR) spectroscopy can improve the effectiveness and rational utilization and management of water resources. However, the accuracy of spectral models of water quality parameters is usually prone to noise information and high dimensionality of spectral data. This study aimed to enhance the model accuracy through optimizing the spectral models based on the sensitive spectral intervals of different water quality parameters. To this end, six kinds of sewage water taken from a biological sewage treatment plant went through laboratory physical and chemical tests. Eight-seven samples of sewage water were obtained by adding different amount of pure water to them. The raw reflectance $\left(R_{\text {raw }}\right)$ of the samples were collected with Analytical Spectral Devices (ASD). The $R_{\text {raw-SNv }}$ were obtained from the $R_{\text {raw }}$ processed with the standard normal variable (SNV). Then, the sensitive spectral intervals of each of the six water quality parameters, namely, COD, BOD, $\mathrm{NH}_{3}-\mathrm{N}$, the total dissolved substances (TDS), total hardness (TD) and total alkalinity (TA), were selected using three different methods: gray correlation $(\mathrm{GC})$, variable importance in projection (VIP) and set pair analysis (SPA). Finally, the performance of both extreme learning machine (ELM) and partial least squares regression (PLSR) was investigated based on the sensitive spectral intervals. The results demonstrated that the model accuracy based on the sensitive spectral ranges screened through different methods appeared different. The GC method had better performance in reducing the redundancy and the VIP method was better in information preservation. The SPA method could make the optimal trade-offs between information preservation and redundancy reduction and it could retain maximal spectral band intervals with good response to the inversion parameters. The accuracy of the models based on varied sensitive spectral ranges selected by the three analysis 
methods was different: the GC was the highest, the SPA came next and the VIP was the lowest. On the whole, PLSR and ELM both achieved satisfying model accuracy, but the prediction accuracy of the latter was higher than the former. Great differences existed among the optimal inversion accuracy of different water quality parameters: COD, BOD and TN were very high; TA relatively high; and TDS and TH relatively low. These findings can provide a new way to optimize the spectral model of wastewater biochemical parameters and thus improve its prediction precision. 
1 Quantitative estimation of wastewater quality

2 parameters by hyperspectral band screening using

3 GC,VIP and SPA

4 Zheng Xing ${ }^{1,2}$, Junying Chen ${ }^{1,2}$, Xiao Zhao ${ }^{1,2}, \mathrm{Yu} \mathrm{Li}^{1}$, Xianwen Li ${ }^{1}$, Zhitao Zhang ${ }^{1}$, Congcong

$5 \mathrm{Lao}^{1}$ and HaiFeng Wang ${ }^{1}$

${ }^{1}$ Key Laboratory of Agricultural Soil and Water Engineering in Arid and Semiarid Areas,

9 Ministry of Education, Northwest A\&F University, Yangling, Shaanxi, China

${ }^{2}$ College of Water Resources and Architectural Engineering, Northwest A\&F University,

11 Yangling, Shaanxi, China 


\section{ABSTRACT}

Water pollution has been hindering the world's sustainable development. The accurate inversion of water quality parameters in sewage with visible-near infrared (VIS-NIR) spectroscopy can improve the effectiveness and rational utilization and management of water resources. However, the accuracy of spectral models of water quality parameters is usually prone to noise information and high dimensionality of spectral data. This study aimed to enhance the model accuracy through optimizing the spectral models based on the sensitive spectral intervals of different water quality parameters. To this end, six kinds of sewage water taken from a biological sewage treatment plant went through laboratory physical and chemical tests. Eight-seven samples of sewage water were obtained by adding different amount of pure water to them. The raw reflectance $\left(R_{\text {raw }}\right)$ of the samples were collected with Analytical Spectral Devices (ASD). The $\mathrm{R}_{\text {raw-SNV }}$ were obtained from the $\mathrm{R}_{\text {raw }}$ processed with the standard normal variable (SNV). Then, the sensitive spectral intervals of each of the six water quality parameters, namely, COD, BOD, $\mathrm{NH}_{3}-\mathrm{N}$, the total dissolved substances (TDS), total hardness (TD) and total alkalinity (TA), were selected using three different methods: gray correlation (GC), variable importance in projection (VIP) and set pair analysis (SPA). Finally, the performance of both extreme learning machine (ELM) and partial least squares regression (PLSR) was investigated based on the sensitive spectral intervals. The results demonstrated that the model accuracy based on the sensitive spectral ranges screened through different methods appeared different. The GC method had better performance in reducing the redundancy and the VIP method was better in information preservation. The SPA method could make the optimal trade-offs between information preservation and redundancy reduction and it could retain maximal spectral band intervals with good response to the inversion parameters. The accuracy of the models based on varied sensitive spectral ranges selected by the three analysis methods was different: the GC was the highest, the SPA came next and the VIP was the lowest. On the whole, PLSR and ELM both achieved satisfying model accuracy, but the prediction accuracy of the latter was higher than the former. Great differences existed among the optimal inversion accuracy of different water quality parameters: COD, BOD and TN were very high; TA relatively high; and TDS and TH relatively low. These findings can provide a new way to optimize the spectral model of wastewater biochemical parameters and thus improve its prediction precision.

Key words: Wastewater quality parameters; Hyperspectral band screening; Gray correlation method; Variable importance projection analysis; Set pair analysis; Extreme learning machine

\section{Introduction}


Water pollution, one of the most important causes for the shortage of the utilizable water resources, has seriously threatened the sustainable development of human society. According to the statistics of The 4th World Water Forum UN World Water Development Report, about 420 billion cubic meters of sewage is poured into rivers and lakes every year, polluting 550 million cubic meters of fresh water, which is equivalent to over $14 \%$ of the total amount of global river. Water quality is affected by the synergy of multiple pollutants (Brönmark \& Hansson, 2002). The excessive presence of these pollutant particles would make the water quality parameters go beyond the current standards, so the water becomes too contaminated to use. Therefore, accurately and efficiently acquiring the water quality parameters of these pollutants can improve the pertinence and effectiveness of water pollution monitoring.

The traditional procedure of quantitatively estimating the water pollutant parameters mainly includes such steps as water sampling at fixed points, physical and chemical examinations in laboratory, and comprehensive statistical analysis. Such a method is not only time-consuming and laborious, but also limited in observation points and representation (Esterby, 1996; Shafique et al., 2003). There are more than 117 million lakes on the earth, only a very small number of which are under regular and continuous monitoring (Verpoorter et al., 2014). Due to the limitations of the traditional method, it is impossible to achieve dynamic monitoring of water quality in large areas.

Different from the conventional methods, remote sensing technology can acquire large-area water spectral information quickly, continuously and inexpensively and obtain by different methods the multiple components information of water from remote sensing images (Bukata \& Bukata, 2005; Arabi et al., 2016; Campanelli et al., 2017; Deng et al., 2017). However, due to the influence of spatial and temporal variation and long transmission distance, about $90-98 \%$ of the signals obtained by the remote sensing are from the surface of the water and the atmosphere, and the remaining $2-10 \%$ of the signals are from the water components. This has led to the complexity of the optical characteristics of water, which has made it rather difficult to identify the information of water pollutants, resulting in the uncertainty in the extraction results of water pollutants (Gitelson \& KONDRATYEV, 1991). In the water, some of the main pollutant parameters (COD, BOD) change the radiation of light through their own absorption and scattering characteristics of light, and thus have different characteristic absorption spectra, which strongly correlates the pollutant content and spectral reflectance (Duan. et al. 2006; Cao. et al. 2018; Wu. et al. 2011). In recent years, hyper-spectral techniques are still being widely used for various monitoring of natural resources. Nowadays, the application of hyper-spectral techniques can facilitate the elimination of the external interference, obtain fine spectral information, and ensure the accuracy of spectral inversion. Therefore, more researchers have deeply studied the application of the hyperspectral technology in obtaining the visible and near-infrared (VIS-NIR) band in order to estimate the content of some pollutants (Palmer et al., 2015; Han \& Rundquist, 1997) 
At present, the inversion of water quality parameters is mainly aimed at the physiological parameters of the water, such as transparency and nutrients (Zhang et al., 2017), but rarely at such biochemical parameters of water as its total hardness (TH), total dissolved matter (TDS), biological oxygen demand (BOD)(Yang et al., 2004), chemical oxygen demand (COD)(Rojas, 2009), total alkalinity (TA), and ammonia nitrogen $\left(\mathrm{NH}_{3}-\mathrm{N}\right)($ Lerch, 2015). These water quality parameters reflect the water pollution degree, which is of great significance for the purposeful and effective treatment of sewage. Among the spectral inversion methods of water quality parameters, the empirical statistical method remains the mainstream. The partial least squares regression (PLSR) (Wold, 1966), as a typical linear regression method, is of wide use in model construction for its advantage of using all available bands without multi-collinearity problem. With the gradual promotion of machine learning algorithms, such advanced semi-empirical machine learning algorithms (Keller et al., 2018) as artificial neural networks (Isiyaka et al., 2018; Bansal \& Ganesan, 2019), support vector machine (SVM), extreme learning machine (ELM) have also been gradually applied in the retrieval of water quality parameters, which have greatly improved the model inversion accuracy. Compared with traditional neural networks, ELM calculates faster with the learning accuracy guaranteed. However, in the process of spectral data modeling, there are two major problems in data processing caused by the large amount of data information of hyperspectrum (Zhang et al., 2018). One problem is that between the adjacent frequency bands usually has a high correlation, which brings huge redundant information. Redundant information is of no use to the processing of hyperspectral data, which will be a great waste of computation and storage. Another problem is that the detailed information of spectrum will increase the dimension of hyperspectral data, which may lead to the "Hughes phenomenon". Hughes phenomenon means the increase of data dimension will decrease the classification accuracy when the number of training samples is limited (Hughes, 1968). Therefore, in current researches, scholars are trying to adopt some methods to screen the characteristic spectrum, to remove redundant information, and to improve the stability and predictability of the model (Feng et al., 2017). The variable importance projection (VIP) algorithm has successfully distinguished the hyperspectral band subsets of forest species by identifying the importance of the independent variables (Peerbhay et al., 2013); The gray correlation (GC) method, using the gray values of the independent variables, has achieved the screening of spectral intervals of soil ion characteristics (Wang et al., 2019). So far these two methods have rarely been applied in the screening of the characteristic spectrum of water pollution parameters. Meanwhile, these band screening methods have different preferences and significant differences in the performance of different modeling methods, which will lead to the uncertainty in the model accuracy (Lerch, 2015). Iterative progressive elimination combined with PLSR has a good performance in the inversion of chlorophyll A and total suspended solids (Wang et al., 2018). VIP combined with PLSR and SVR has significantly improved the inversion effect of characteristic spectra of water-soluble ions in soil, while GC combined with PLSR and SVR showed relatively poor inversion effect (Wang et al., 2019). However, GC combined with ELM has a good effect on the prediction and inversion of total nitrogen content in soil (Zhou et al., 2017). Moreover, in order for the better universality and stability of band selection method, 
147 the set pair analysis (SPA) theory was used to establish models which can identify the overall 148 degree as well as the important indicators and subsystems in the influencing factors (Zhang et al., 149 2019). SPA theory, for its remarkable capability of dealing with uncertain problems, has been 150 widely applied in many fields (Wang et al., 2017; Li et al., 2016), but not yet applied in band 151 selection. This research applied the band selection methods of GC, VIP and SPA to select from 152 hyperspectral data the feature subsets, which were used to establish PLSR and ELM models to 153 estimate such water quality parameters as $\mathrm{COD}, \mathrm{BOD}, \mathrm{NH}_{3}-\mathrm{N}$ TDS TH and TA, and to compare and analyze the inversion effects of different pollutant indicators.

155 Particularly, the study aims to: (1) determine the optimal spectral interval corresponding to the 156 six water pollution indicators, build the optimal inversion models of six water pollution 157 parameters, and achieve quantitative estimation of water pollution parameters through hyperspectrum; (2) verify the SPA method in weighing the different wavelength screening methods and provide an approach to band selection by applying the set optimization idea; (3) determine the corresponding optimal models for different water quality parameters by comparing the performance of GC, VIP and SPA models.

\section{MATERIALS AND METHODS}

\section{Sample preparation and chemical analysis}

The water samples were taken from different spots (water inlet, anoxic tank, aerobic tank, sedimentation tank and water outlet) under different treatment methods at a domestic sewage treatment plant in China. The domestic sewage treatment plant gave field permit approval to us (NO.51409221, 51979234). According to our pre-analysis (Table 1), the water samples collected at the inlet were abundantly rich in COD, BOD and NH3-N (COD: 425mg/L, BOD: 101.15mg/L, NH3-N: $34.853 \mathrm{mg} / \mathrm{L}$ ), whilst the water samples collected in other treatment ponds were relatively low in COD of $20 \sim 140 \mathrm{mg} / \mathrm{L}$, BOD of $3.1 \sim 13 \mathrm{mg} / \mathrm{L}$ and NH3-N of $0 \sim 1.723 \mathrm{mg} / \mathrm{L}$. Such large variations suited well to represent the range of water quality collected from different locations investigated in this study, but also leaving non-negligible deficiency in representing water quality of moderate concentrations. Therefore, to make the hyperspectral model more robust and responsive to minor changes of water quality at other potential locations, we further diluted the water samples into subsamples to form a full range of distribution within the minimum and maximum values detected in this study. To be specific, following the minimum and maximum COD measured from the inlet and other treatment ponds, the water samples rich in COD were diluted by adding different amount of pure water, forming different COD concentrations varying at unit of $5 \mathrm{mg} / \mathrm{L}$. In total, 87 water samples were obtained to establish the hyperspectral model and strengthen its applicability. In a real application of hyperspectral model, the water quality of targeted samples often covers a variety of concentrations, and thus can be measured and applied directly without any dilution. The laboratory was kept in a constant 
183

184

185

186

187

188

189

190

191

192

193

194

195

196

197

198

199

200

201

202

203

204

205

206

207

208

209

210

temperature during the experiments. The main water quality parameters included $\mathrm{NH}_{3}-\mathrm{N}$, TA, TH, TDS, COD and BOD.

\section{Acquisition and pretreatment of spectral data}

The wastewater samples were put into black cylindrical cups with a depth of $5 \mathrm{~cm}$ and a diameter of $10 \mathrm{~cm}$ for spectral data collection in the laboratory. The hyperspectral data for wastewater samples were measured using an ASD (Analytical Spectral Devices, Inc. Boulder, CO, USA) FieldSpec $® 3$ spectrometer with spectral range from 350 to $2500 \mathrm{~nm}$. The instrument was equipped with one sensor with $1.4 \mathrm{~nm}$ spectral resolution for the range of 350$1000 \mathrm{~nm}$ and the other sensor $2 \mathrm{~nm}, 1000-2500 \mathrm{~nm}$. The spectral data were collected in a dark room by exposing the water sample surfaces to a halogen lamp of $50 \mathrm{~W}$ above with a $30^{\circ}$ of incident angle and $50 \mathrm{~cm}$ in distance and a fiber-optics probe $5^{\circ}, 15 \mathrm{~cm}$, so as to minimize the effects of external factors (Wang \& Zhao, 2000). Before each measurement, we had fully preheated the spectrometer and light source and checked the spectrometer with a standardized white panel of $99 \%$ reflectance in order to reduce measurement errors. Each water sample was measured twice vertically, and at each of which the spectral data were gathered ten times. Altogether there were 20 spectrum curves for each sample (Hong et al., 2018). From the 20 curves the raw spectral reflectance $\left(\mathrm{R}_{\text {raw }}\right)$, namely, arithmetic mean, were obtained by using ViewSpecPro software (6.0 version). The fluctuation of $\mathrm{R}_{\text {raw }}$ would influence the accuracy of subsequent modeling due to the disturbance of the random error, instrument noise and external environment in spectral data collection. In general, the external noise can be eliminated to some degree with such effective pretreatments as resampling, smoothing and transformation, which can improve the spectral characteristics (Ding et al., 2018). Therefore, two steps were adopted to pretreat the $R_{\text {raw }}$ : (1) removing the marginal wavelengths $(2,401-2,500 \mathrm{~nm}$ and $350-399 \mathrm{~nm})$ of higher noise in each water sample, then smoothing the remaining spectrum data through filter method (polynomial order = 2; window size $=5$ ) of Savitzky-Golay (SG) (Savitzky\&Golay,1964) by Origin Pro software (2017SR2 version); and (2) obtaining the precise $\mathrm{R}_{\text {raw-SNV }}$ using the standard normal variable (SNV) to remove the effects of baseline shift and surface scattering on the spectral data (Xiao et al., 2016). The spectral curves of $\mathrm{R}_{\text {raw }}$ and $\mathrm{R}_{\text {raw-SNV }}$ are shown in Figs. $1 \mathrm{~A}$ and 1B. As can be seen, the spectral curve in Fig. 1B is much smoother than that in Fig. 1A.

\section{Wavelength selection methods}

\section{Gray correlation (GC)}

The GC method, one of the grey system theories, seeks the primary and secondary relations and analyzes the different effects of all the factors in a system (Ju-Long, 1982; Liu, Yang \& Wu, 2015).The gray correlation degree (GCD), varying from one moment and object to the other, refers to the measurement of the factor correlation between two systems. In the process of system development, higher consistency of change trend of the two factors reflects higher correlation 
219 degree and vice versa (Zhu et al., 2017). The main calculation steps are: first, determining

signature and factor sequences with the former marked as $x_{0}(t)$ which is a collection of $m$ data-$x_{0}(t)=\left\{x_{0}(1), x_{0}(2), \ldots, x_{0}(m)\right\}$ and the latter marked as $x_{i}(t)$ which contains $n$ sub-sequences with each as a collection of $m$ data-- $x_{i}(t)=\left\{x_{i}(1), x_{i}(2), \ldots, x_{i}(m)\right\}$; and second, processing the data sequences dimensionlessly using averaging operators. $X_{i}=\left\{x_{i}(1), x_{i}(2), \ldots, x_{i}(m)\right\}$ represents the behavior sequence of factor $x_{i}$ and $D$ the averaging sequence operator, and thus $X_{i} D=\left\{x_{i}(1) d, x_{i}\right.$ (2) $\left.d, \ldots, x_{i}(m) d\right\}$. So the mean data value is calculated as

$$
\begin{gathered}
x_{i}(k) d=\frac{x_{i}(k)}{\overline{X_{i}}}, \overline{X_{i}}=\frac{1}{n} \sum_{k=1}^{n} x_{i}(k) \quad k=1,2, . ., n \\
\xi_{0 i}(t)=\frac{\Delta_{\min }+\rho \Delta_{\max }}{\Delta_{0 i(t)}+\rho \Delta_{\max }}
\end{gathered}
$$

where $\Delta_{\text {max }}$ is the maximum of $\left|x_{0}(t)-x_{\mathrm{i}}(t)\right| ; \Delta_{\text {min }}$ is the minimum of $\left|x_{0}(t)-x_{\mathrm{i}}(t)\right| ;\left|x_{0}(t)-x_{\mathrm{i}}(t)\right|$ is the value at time $\mathrm{t} ; \rho$ is the coefficient of discrimination. Therefore, GCD between the signature and factor sequences is calculated as

$$
\gamma_{0 i}=\frac{1}{n} \sum_{t=1}^{n} \xi_{0 i}(t)
$$

From the interaction between the signature and factor sequences, the factors' primary and secondary influences can be predicted (Wang et al., 2018). In this paper, the higher the GCD of a certain band is, the more sensitive the band is to the water quality parameter, and vice versa.

\section{Variable importance projection}

The VIP is a variable screening analysis method based on PLSR model. The VIP value of a spectral variable reflects the importance of this variable in the prediction of the substance to be measured (Oussama et al., 2012; de Almeida et al., 2013). The VIP value reflects the explanatory power of independent variable over dependent variable, and represents the importance of independent variable to model fitting (Chavana-Bryant et al., 2019). If the explanatory ability of each variable to $\mathrm{Y}$ is the same, then the VIP value of all independent variables is 1 . If the VIP value of an independent variable is less than 1, it means that the variable makes little contribution to the model and has a very low ability to explain the dependent variable, so it can be eliminated. In the PLSR model, $\mathrm{VIP}_{i}$ to an independent variable $\mathrm{X}_{i}$ is defined as:

$$
V I P_{i}=\sqrt{\frac{p^{*} \sum_{h=1}^{m} R d\left(Y ; t_{h}\right) W_{h j}^{2}}{R d\left(Y ; t_{1}, t_{2}, \cdots, t_{m}\right)}}
$$

where $p$ is the dimension of independent variable; $t_{h}$ is the component $h ; m$ is the number of components selected in the model; $W_{h j}$ is the component of $X_{j}$ corresponding to axis $W_{h} ; R d(Y$; $T_{h}$ ) represents the variation of $Y$ explained by the component $t_{h}$; and $R d\left(\mathrm{Y} ; t_{1}, t_{2}, \cdots t_{m}\right)$ represents the cumulative variation accuracy of $\mathrm{Y}$ explained by $t_{l} \sim t_{m}$. In PLSR model, the explanatory power of $x_{j}$ over $\mathrm{Y}$ is passed through $t_{h}$, so if $t_{h}$ bears a strong explanatory power over $\mathrm{Y}$, and 
251 meanwhile $x_{j}$ plays a very important role in the process of $t_{h}$ construction, $t_{h}$ can be reasonably 252 regarded as very important variable in explaining $Y$. In this way of wavelengths selection, the 253 wavelengths with strong explanatory power are reserved while those with weak explanatory 254 power are eliminated (Chemura et al., 2017).

\section{Set pair analysis (SPA)}

256 SPA integrates uncertainty analysis and determinacy analysis (Zhao, 1996). The basis of SPA is 257 set pair whose key is correlation degree, which has been applied as a criterion for the analysis of certainty and uncertainty (Zhang et al., 2019). During the hyperspectral band selection, the GC value $\mathrm{Y}_{i}=\left(y_{1}, y_{2}, \cdots, y_{n}\right)$ can be defined as set $\mathrm{A}$, and VIP value $Z_{i}=\left(z_{1}, z_{2}, \cdots, z_{n}\right)$ as set $\mathrm{B}$, and then the two sets compose a set pair $\mathrm{H}=(\mathrm{A}, \mathrm{B})$. To study the correlation degree of the set pair, the formulas are as follows:

$$
\mu_{i}=S_{i}+F_{i} * I_{i}+P_{i}^{*} J=\frac{S_{i}}{\mathrm{n}}+\frac{f_{i}}{\mathrm{n}} I_{i}+\frac{p_{i}}{\mathrm{n}} J
$$

$$
I_{i}=\frac{S_{i}-P_{i}}{S_{i}+P_{i}}
$$

where $S_{i}, F_{i}, P_{i}$ are the identity degree, discrepancy degree and opposite degree of the two sets in the context of the same problem, respectively. They describe the association of the two sets from different aspects. $S_{i}, F_{i}, P_{i}$ meet the relationship: $S_{i}+F_{i}+P_{i}=1$, n denotes the total number of characteristics of the set pair; $s_{i}$ is the number of the common characteristics of the two sets; $f_{i}$ is the number of the different characteristics of the two sets (Li et al., 2016); $p_{i}$ is the number of the opposite characteristics of the two sets. When $J=-1$, the contact number $u_{i}$, the relative membership degree $v_{i}$, and the weighted value, $W_{i}$, of the VIP value and GC value, were calculated.

\section{Model construction and validation}

\section{Classification of modeling and validation sets}

Kennard-Stone algorithm (K-S) (Kennard \& Stone, 1969) was used to classify the sample sets to select representative calibration sample sets. K-S was used to calculate the minimum Euclidean distance of the unselected samples according to the selected samples. Then the samples with the maximum Euclidean distance were selected into the calibration set in a repeated way until the samples of a specified number were selected. K-S algorithm has turned out to be effective in selecting representative samples (Morais et al., 2019). Two-third of the water quality samples 
283

284

285

286

287

288

289

290

291

292

293

294

295

296

297

298

299

300

301

302

303

304

\section{Modeling methods and evaluation}

The PLSR and ELM methods were applied to the quantitative inversion of different water quality parameters in this paper. The PLSR model has been widely applied and can overcome the multicollinearity of independent variables because of its dimensionality reduction, information integration and band optimization in the modeling process, which has greatly improved the ability of the system to extract principal components (Ryan \& Ali, 2016). The ELM is a machine learning algorithm based on feed forward neural network. It has the advantages of high learning efficiency, high accuracy and simple parameter adjustment over the traditional feed forward neural network (Song et al., 2013). The optimal model was selected to inverse the water quality parameters through comparing the models' root mean square error of calibration (RMSEC), determination of coefficients $\left(R_{c}^{2}\right)$, root mean square error of prediction (RMSEP), prediction determination of coefficients $\left(R_{p}^{2}\right)$ and relative prediction deviation (RPD). $R_{c}^{2}$ and $R_{p}^{2}$ are used to evaluate the stability degree of a model. The closer its value is to 1 , the higher stability the model has. RMSEC and RMSEP represent the accuracy of the model. The smaller their value is, the higher the model accuracy is. A model is considered excellent when RPD $>3.0$, very good when $2.5<\mathrm{RPD} \leqslant 3$, good when $2<\mathrm{RPD} \leqslant 2.5$, satisfactory when $1.5<\mathrm{RPD} \leqslant 2$ and poor when $\mathrm{RPD} \leqslant 1.5$ (Williams, 2001) .

\section{RESULT AND ANALYSIS}

\section{Correlation between water quality parameters content and spectral reflectance}

The Pearson correlation coefficients between each water quality parameter and the $\mathrm{R}_{\text {raw-SNV }}$ $(400-2400 \mathrm{~nm})$ were tested with the significance level $(\mathrm{P}<0.001,|\mathrm{r}|=0.324$ or above). The curves of correlation coefficients of water quality parameters were plotted in Fig. 2.

The change of the correlation coefficients of water quality parameters was complex. There were significant differences in the correlation coefficients between different water quality parameters and the wavelengths but their curve patterns were similar (Peng et al., 2018). There were many concentrated similar sensitive ranges but in general, the curves took "sharp fall, fluctuation, and oscillation" (Fig. 2). The $\mathrm{COD}, \mathrm{BOD}, \mathrm{NH}_{3}-\mathrm{N}$ and TA were all highly correlated and represented a positive correlation (the correlation coefficients $>0.6$ ) at the wavelengths of $900 \sim 1300 \mathrm{~nm}$ and $1500 \sim 1800 \mathrm{~nm}$. In contrast, the correlation between the total dissolved substances and spectral data and that between the TH and spectral data were not so satisfied (the correlation coefficients $<0.6)$. The six parameters could pass the test of significance $(\mathrm{P}=0.001)$ at the wavelengths of $400 \sim 450 \mathrm{~nm}$ and $850 \sim 1800 \mathrm{~nm}$. The band range was wide and the peak value of the correlation coefficients was relatively flat, so it was difficult to screen the characteristic 
316

317

318

319

320

321

322

323

324

325

326

327

328

329

330

331

332

333

334

335

336

337

338

339

340

341

342

343

344

345

346

347

348

349

350

351

bands based on the correlation coefficients.

\section{Selection of characteristic wavelength}

\section{GC-based selection of Characteristic wavelength}

The curves of GCD for water quality parameters and $\mathrm{R}_{\text {raw-SNV }}$ are shown in Fig. 3. An obvious peak wavelength appeared in the curves with the similar patterns of "sharp rise, fall and stabilization" on the whole (Fig. 3). The gray value of each water quality parameter gradually went up from $400 \mathrm{~nm}$ to a peak at about $820 \mathrm{~nm}$, and then gradually down to $1000 \mathrm{~nm}$ where it remained flat. The overall gray values of TDS and TH were relatively high, generally above 0.5, while those of COD, BOD, $\mathrm{NH}_{3}-\mathrm{N}$ and TA were generally between 0.3 and 0.4 with only a few peak bands greater than 0.4 and above 0.8 at the most. It reflected that the gray correlation method excels in eliminating a great amount of redundant information and selecting a few most sensitive bands.

The sensitive bands of the six parameters were counted based on their GCD analysis (Table 2). Of all the GCD values, the maximum ones were concentrated within the spectral wavelengths of $815 \sim 830 \mathrm{~nm}$. The numbers of the sensitive bands were sequenced from large to small as: TH (601) $>\operatorname{TDS}(381)>\mathrm{TA}(93)>\mathrm{BOD}(50)>\mathrm{COD}(49)>\mathrm{NH}_{3}-\mathrm{N}(46)$, and those of the maximum GCD values as: $\mathrm{TH}(0.8504)>\mathrm{TDS}(0.802)>\mathrm{BOD}(0.7974)>\mathrm{NH}_{3}-\mathrm{N}(0.7973)>\mathrm{COD}(0.7949)>\mathrm{TA}$ (0.7878). The comparison between the correlation coefficients and the GCD indicated a great difference: the higher correlation coefficient the parameters had, the lower the GCD values was, and the smaller number of sensitive bands were selected. This result revealed that for the parameters with strong spectral response the GCD method had better band screening ability.

\section{VIP-based selection of Characteristic wavelength}

The curves of VIP scores for water quality parameters and $R_{\text {raw-SNV }}$ are shown in Fig. 4. The curves patterns of the six parameters were similar and the overall scores of the VIP were relatively high (Fig. 4). These curves exhibited a sharp drop in the wavelength intervals of $400 \sim 450 \mathrm{~nm}$, a sharp rise in 460 500nm, a violent fluctuation in $700 \sim 1000 \mathrm{~nm}$, but in 1100 2000nm TH and TDS displayed a less violent fluctuation and COD, BOD, $\mathrm{NH}_{3}-\mathrm{N}$ and TA showed flat fluctuation. Many peak points existed in the VIP curves, and their peak intervals were relatively scattered, completely different from the single peak value in the GC curves. The principle of VIP $>1$ was used to select and count the spectral sensitive bands of the six parameters (Table 3). The comparison of the maximum spectral response bands showed five parameters were found in the wavelength intervals of $460 \sim 480 \mathrm{~nm}$ except for $\mathrm{NH}_{3}-\mathrm{N}$ in 990 999nm.

The numbers of sensitive bands selected through VIP method were sequenced from large to small as $\mathrm{BOD}(770)>\mathrm{NH}_{3}-\mathrm{N}(768)>\mathrm{COD}(753)>\mathrm{TA}(709)>\mathrm{TH}(543)>\mathrm{TDS}(497)$, and those of the maximum VIP scores as: TH (4.893) > TDS (4.275) > TA (2.466) > COD (1.634) > 
352 BOD (1.439) $>\mathrm{NH}_{3}-\mathrm{N}$ (1.397). The comparison between the two sequences indicated a great 353 difference: the larger the VIP score was, the smaller number of selected sensitive bands was. On 354 the whole, the effective bands could be retained as many as possible with the VIP method during 355 bands screening.

\section{SPA-based selection of Characteristic wavelength}

The curves of SPA scores for water quality parameters and $R_{\text {raw }-S N V}$ are shown in Fig.5. The curves patterns of TDS and TH were similar and exhibited a gentle flatness except for obvious peaks at the wavelengths of about $460 \mathrm{~nm}$ and $990 \mathrm{~nm}$. Those of $\mathrm{BOD}, \mathrm{NH}_{3}-\mathrm{N}$ and TA were similar and showed notable valleys at the wavelengths of about $500 \mathrm{~nm}$ and $700 \mathrm{~nm}$ and notable peaks at the wavelengths of about 760nm and 1000nm. Those of COD displayed notable peaks at the wavelengths of about $460 \mathrm{~nm}$ and $1000 \mathrm{~nm}$ and fluctuation at other wavelengths. On the whole, great difference existed among the six curves, and the sensitive interval of each parameter was quite notable and different from each other.

The principles of GCD $>0.5$ and VIP $>1$ were used to select and count the spectral sensitive bands of the six parameters (Table 4). The comparison of the maximum spectral response bands revealed $\mathrm{NH}_{3}-\mathrm{N}$ was in the wavelength intervals of 990 999nm, BOD in 760 770nm and the other four in $460 \sim 475 \mathrm{~nm}$. The numbers of sensitive bands selected through SPA method were arranged in a descending order as: $\mathrm{BOD}(767)>\mathrm{NH}_{3}-\mathrm{N}(765)>\mathrm{COD}(750)>\mathrm{TA}(696)>\mathrm{TDS}$ $(280)>\mathrm{TH}$ (223), the scores of the maximum SPA as: TA (2.409) > TH (1.944) > TDS (1.928) > COD (1.598) $>$ BOD (1.409) $>\mathrm{NH}_{3}-\mathrm{N}$ (1.364). The comparison between the two orders indicated a great difference: the larger the SPA score was, the smaller number of the selected sensitive bands had.

\section{Construction and analysis of PLSR model}

The sensitive bands selected by different methods as GC, VIP and SPA were applied to PLSR modeling. The results of PLSR model are shown in Table 5.

In general, the PLSR model had a good spectral prediction of water quality parameters (Wang et al,. 2019). The GC-PLSR model was proved to be optimal for COD, BOD, NH3-N and TH with the best prediction. SPA-PLSR model was proved to be optimal for TDS and TA with the best prediction (Table 5). The VIP-PLSR model of BOD had the best modeling effect $\left(R^{2}{ }_{c}=\right.$ 0.99). The GC-PLSR model of $\mathrm{NH}_{3}-\mathrm{N}$ had the best prediction effect $\left(R_{p}^{2}=0.962, \mathrm{RPD}=5.894\right)$. The inversion effects of TDS and TH were relatively less satisfying, with the $R_{c}^{2}$ and $R_{p}^{2}$ generally around 0.8 . Overall, the PLSR models based on the characteristic bands of the six parameters exhibited good modeling and prediction effect as well as a greater improvement than those full band-based models.

\section{Construction and analysis of ELM model}

The sensitive bands selected using GC, VIP and SPA methods were applied to build ELM model. 
The results of ELM model are shown in Table 6.

The ELM models based on the characteristic bands of the six parameters exhibited good modeling and prediction effect as well as a greater improvement than those based on the full band. The GC-ELM model was proved optimal for $\mathrm{COD}, \mathrm{BOD}$ and $\mathrm{NH}_{3}-\mathrm{N}$ with the best prediction. SPA-ELM was proved optimal for TDS, TA and TH with the best prediction. The VIP-ELM model of BOD had the best modeling effect $\left(R^{2}{ }_{c}=0.986\right)$. The GC-ELM model of $\mathrm{NH}_{3}-\mathrm{N}$ exhibited the best prediction effect $\left(R_{p}^{2}=0.976, \mathrm{RPD}=6.596\right)$. The ELM models of COD, TH and TA had the satisfying modeling and validation effect. The validation effect of TDS was relatively less satisfying $\left(R_{c}^{2}=0.820, R_{p}^{2}=0.790, \mathrm{RPD}=2.198\right)$.

\section{DISCUSSION}

\section{Comparison among the estimating results of different water quality parameters}

The optimal wavelength selection methods varied when the optimal modeling methods were different (Tables 5 and 6). The hyper-spectrally estimated value and the chemically measured value of the six water quality parameters were compared under the optimal model (Fig. 6).

Different water components can change the spectral radiation by their own absorption and scattering characteristics of light. The water components (such as SPM, CDOM, phytoplankton, blue-green algae) can be obtained by separating the factors of various parameters from the total water radiation (Dörnhöfer \& Oppelt, 2016). However, the problem of "lower ion content and weaker spectral response" often exists in the spectral analysis of water components, and was also reflected in the verification results of this study. All the six parameters produced satisfying inversion results, which indicated the feasibility of quantitative inversion of sewage water quality parameters by hyperspectrum $(\mathrm{Pu}$ et al., 2017). The sequence of the predicting power of the water quality parameters was $\mathrm{NH}_{3}-\mathrm{N}>\mathrm{BOD}>\mathrm{COD}>\mathrm{TA}>\mathrm{TH}>\mathrm{TDS}$. The validation results showed that most data points of the five water parameters, $\mathrm{NH}_{3}-\mathrm{N}, \mathrm{BOD}, \mathrm{COD}$, TA and $\mathrm{TH}$, were concentrated near line 1:1. This indicated that the hyperspectral analysis values of the five parameters were very close to the chemically estimated values and the optimal models of these five parameters had strong prediction ability (RPD>3.0) (Tables 5 and 6). Comparatively, due to its lower content, the data points of TDS were relatively discrete, indicating that the model prediction ability was average $(\mathrm{RPD}=2.198)$.

\section{Correlation analysis and inversion performance}

The raw spectral reflectance curve of each water sample exhibited different shapes (Fig. 2A). This difference results from the inconsistency between the contents and types of the water quality parameters, and the different characteristics of spectrum obtained through absorption and scattering of light. The results accord with those in previous studies (Abdelmalik, 2018; AbdElrahman et al., 2011; Rostom et al., 2017; Wang et al., 2016), which demonstrates that the VIS- 
NIR spectrum can be used to quantitatively determine water quality parameters.

Traditionally, correlation analysis is helpful to reveal the relationship between water quality parameters and the VIS-NIR spectrum (Peng et al., 2018). In this paper, the numbers of the significant wavebands of the six water quality parameters can be arranged in an order, in which the numbers of $\mathrm{NH}_{3}-\mathrm{N}, \mathrm{BOD}$ and $\mathrm{COD}$ were close to one another but larger than those of the other three parameters. The number of TA followed, and those of TH and TDS came last. This order agreed with that of their correlation coefficient ranges. Therefore, significant correlations exist between $\mathrm{NH}_{3}-\mathrm{N}, \mathrm{BOD}, \mathrm{COD}$ and their reflectance spectrum, which reflects the optimal models of the three parameters have a very good prediction performance (Fig. 6). By contrast, the correlations between the other three water quality parameters and their reflectance spectrum were relatively low, which led to poor model prediction performance, especially for the TDS model. However, by comparing the three screening methods, the numbers of the sensitive wavebands of TA, TH and TDS were not as small as had been expected (Tables 3, 4, 5). This is because different waveband screening methods use different calculation mechanisms, which leads to different methods to screen optimal response spectrum for different parameters (Zhang et al., 2018). From the perspective of modeling methods, ELM model performed better than PLSR model, which also indicated the superiority and strong learning ability of machine learning algorithm (Keller S et al. 2018). From the perspective of band selection methods, GC and SPA are superior to VIP. Therefore, the selection of band screening methods will be of practical significance for the quantitative inversion of water quality parameters in the future research.

\section{Effects of wavelength selection on hyperspectral estimation models}

In the process of hyperspectral analysis, due to the mass of hyperspectral information, there exists a large amount of redundant information irrelevant to parameters content. This makes it difficult to mine and extract effective information. This problem complicates the hyperspectral analysis and decrease the analysis accuracy, which hinders the development and utilization of related testing equipment. Therefore, characteristic selection of hyperspectral data information is required. The characteristic selection methods are devised to find the smallest subset from the original characteristics without reducing the accuracy (Zhang et al., 2018). For the hyperspectral band selection, there are two key aspects, namely, effective information preservation and redundancy elimination, which has a great impact on subsequent modeling and validation.

In this study, GC and VIP methods were used to explore their spectral characteristic response intervals for six main water quality parameters in wastewater. These two methods had their fixed preferences in terms of information preservation and redundancy elimination. Therefore, the two methods had quite different performance in the band selection for the parameters and modeling methods, and their performance was very unstable (Wang et al., 2019). Of the two methods, the GC method had better performance in redundancy elimination. Better spectral response of the 
459 water quality parameters means smaller number of bands filtered by the GC method, so the GC 460 method is the best screening method for $\mathrm{COD}, \mathrm{BOD}$ and $\mathrm{NH}_{3}-\mathrm{N}$ with a satisfying screening 461 performance in this study.

462 However, the VIP method performed better in information preservation, and it could retain as 463 many spectral band intervals with good response to the inversion parameters as possible 464 (Oussama et al., 2012; de Almeida et al., 2013). So, the VIP method retained the largest number 465 of bands during band selection. Meanwhile, compared with the GC method, VIP was more applicable to characteristic band selection of TA and TDS.

As to this condition, some researchers considered it necessary to make the optimal trade-offs between information preservation and redundancy elimination according to the different characteristics of the datasets, and have conducted some explorations (Zhang et al., 2018). This study put forward a band screening method based on SPA to optimize the trade-offs between GC and VIP. From its application to the datasets in this study, the SPA method could well balance effective information retaining and redundant information eliminating. Compared with GC and VIP, the SPA method had a more stable ability of band screening. It had a strong applicability to predicting the six water quality parameters as well as building the linear modeling method PLSR and the nonlinear modeling method ELM. Therefore, the SPA method had the superiority in certainty and uncertainty analysis of characteristic bands, and it is applicable to the integrative optimization of GC and VIP.

\section{Research limitations and future research}

This study was only the statistical application of characteristic band screening methods to the inversion of different water quality parameters and failed to explore the spectral response mechanism of the various water quality parameters (Hu \& Wang, 2017), which would lead to some limitations in the applicability of the model. Meanwhile, the optimized band screening method based on the SPA needs further study, which can focus on further: (1) exploring the different spectral sensitive intervals and analyzing the spectral response mechanism of each water quality parameter.

(2) probing into the band screening mechanism and optimizing various screening methods so as to propose a band screening method suitable for various models; and applying various screening methods at the same time in the longitudinal study to achieve multiple screening.

\section{CONCLUSIONS}

This paper studied the feasibility of quantitatively estimating water quality parameters via VISNIR spectral model. The GC, VIP and SPA methods were used to screen the sensitive intervals based on the spectral responses of different water quality parameters in sewage. The inversion accuracy of the six water quality parameters by the linear PLSR and nonlinear ELM modeling 
494

495

496

497

498

499

500

501

502

503

504

505

506

507

508

509

510

511

512

513

514

515

516

517

518

519

520

521

522

523

524

525

526

527

528

529

530

methods was compared, and finally the research arrived at the following conclusions:

1. Band screening plays an important role in spectral data processing and spectral model accuracy improvement. In this study, the $\mathrm{GC}$ had the best performance in redundancy elimination (up to 97\%), the VIP performed best in information preservation, and the SPA could make the optimal trade-offs between information preservation and redundancy reduction, so the SPA had the best applicability.

2. Both the PLSR and ELM models have good performance in modeling and validation. The PLSR model was more applicable and the ELM model had higher prediction accuracy. Among the six corresponding optimal models for the six water quality parameters, five were ELM models while only one was PLSR model.

3. The optimal spectral inversion models of the six water quality parameters had quite different validation results: the prediction of the $\mathrm{COD}, \mathrm{BOD}, \mathrm{NH}_{3}-\mathrm{N}$ and TA models was quite satisfying (their RPD values are 4.69, 6.192, 6.596 and 3.651, respectively), while that of the TH and TDS was relatively poor.

\section{ACKNOWLEDGEMENTS}

The authors want to thank A.P. Ying Meng and Yinwen Chen for their help in language standardization of this manuscript and providing helpful suggestions. We are especially grateful to the reviewers and editors for appraising our manuscript and for offering instructive comments.

\section{REFERENCE}

Abdelmalik, K.W. 2018. Role of statistical remote sensing for Inland water quality parameters prediction. The Egyptian Journal of Remote Sensing and Space Science 21:193-200. 10.1016/j.ejrs.2016.12.002

Abd-Elrahman, A., Croxton, M., Pande-Chettri, R., Toor, G.S., Smith, S., and Hill, J. 2011. In situ estimation of water quality parameters in freshwater aquaculture ponds using hyperspectral imaging system. ISPRS JOURNAL OF PHOTOGRAMMETRY AND REMOTE SENSING 66:463-472. 10.1016/j.isprsjprs.2011.02.005

Arabi, B., Salama, M., Wernand, M., and Verhoef, W. 2016a. MOD2SEA: A Coupled Atmosphere-Hydro-Optical Model for the Retrieval of Chlorophyll-a from Remote Sensing Observations in Complex Turbid Waters. Remote Sensing 8:722. 10.3390/rs8090722

Arabi, B., Salama, M., Wernand, M., and Verhoef, W. 2016b. MOD2SEA: A Coupled Atmosphere-Hydro-Optical Model for the Retrieval of Chlorophyll-a from Remote Sensing Observations in Complex Turbid Waters. Remote Sensing 8:722. 10.3390/rs8090722

Bansal, S., and Ganesan, G. 2019. Advanced Evaluation Methodology for Water Quality Assessment Using Artificial Neural Network Approach. WATER RESOURCES MANAGEMENT 33:3127-3141. 10.1007/s11269-01902289-6

Brönmark, C., and Hansson, L. 2002. Environmental issues in lakes and ponds: current state and perspectives. ENVIRONMENTAL CONSERVATION 29:290-307. 10.1017/S0376892902000218

Bukata, R.P., and Bukata, R.P. 2005. Satellite monitoring of inland and coastal water quality: retrospection, introspection, future directions. Crc Taylor \& Francis.

Peer] reviewing PDF | (2019:07:39875:2:0:NEW 6 Nov 2019) 
531 Campanelli, A., Pascucci, S., Betti, M., Grilli, F., Marini, M., Pignatti, S., and Guicciardi, S. 2017. An Empirical

532 Ocean Colour Algorithm for Estimating the Contribution of Coloured Dissolved Organic Matter in North-Central

533 Western Adriatic Sea. Remote Sensing 9:180. 10.3390/rs9020180

534 Cao Y, Ye Y., Zhang X., Shi Y., Jiang Y., and Zhao h. 2015. Turbidity hyperspectral inversion model of nansihu 535 water body. Water diversion from south to north and water conservancy technology 13:883-887 (in Chinses).

536 CESP. 2002. Analysis methods for water and wastewater monitoring . 4th ed., Beijing: China Environmental 537 Science Press(in Chinese).

538 Chavana-Bryant, C., Malhi, Y., Anastasiou, A., Enquist, B.J., Cosio, E.G., Keenan, T.F., and Gerard, F.F. 2019.

539 Leaf age effects on the spectral predictability of leaf traits in Amazonian canopy trees. SCIENCE OF THE TOTAL

540 ENVIRONMENT 666:1301-1315. 10.1016/j.scitotenv.2019.01.379

541 Chemura, A., Mutanga, O., and Dube, T. 2017. Separability of coffee leaf rust infection levels with machine

542 learning methods at Sentinel-2 MSI spectral resolutions. PRECISION AGRICULTURE 18:859-881.

543 10.1007/s11119-016-9495-0

544 Duan H., Wen Y, Zhang B, Song K., and Wang Z.. 2006. Quantitative inversion of water quality parameters in 545 chagan lake using hyperspectral data. Journal of Arid Land Resources and Environment:104-108(in Chinses).

546 Deng, Y., Zhang, Y., Li, D., Shi, K., and Zhang, Y. 2017. Temporal and Spatial Dynamics of Phytoplankton

547 Primary Production in Lake Taihu Derived from MODIS Data. Remote Sensing 9:195. 10.3390/rs9030195

548 Ding, J., Yang, A., Wang, J., Sagan, V., and Yu, D. 2018. Machine-learning-based quantitative estimation of soil 549 organic carbon content by VIS/NIR spectroscopy. PeerJ 6. 10.7717/peerj.5714

550 Dörnhöfer, K., and Oppelt, N. 2016. Remote sensing for lake research and monitoring - Recent advances. 551 ECOLOGICAL INDICATORS 64:105-122. 10.1016/j.ecolind.2015.12.009

552 Esterby, S.R. 1996. Review of methods for the detection and estimation of trends with emphasis on water quality 553 applications. HYDROLOGICAL PROCESSES 10:127-149.

554 Feng, X., Li, G., Yu, H., Wang, S., Yi, X., and Lin, L. 2017. Wavelength selection for portable noninvasive blood 555 component measurement system based on spectral difference coefficient and dynamic spectrum. Spectrochimica 556 Acta Part A Molecular \& Biomolecular Spectroscopy 193:40.

557 Gitelson, A.A., and KONDRATYEV, K.Y. 1991. Optical models of mesotrophic and eutrophic water bodies. 558 INTERNATIONAL JOURNAL OF REMOTE SENSING 12:373-385.

559 Han, L.H., and Rundquist, D.C. 1997. Comparison of NIR/RED ratio and first derivative of reflectance in estimating 560 algal-chlorophyll concentration: A case study in a turbid reservoir. REMOTE SENSING OF ENVIRONMENT 561 62:253-261. 10.1016/S0034-4257(97)00106-5

562 Hong, Y., Chen, Y., Lei, Y., Liu, Y., Liu, Y., Yong, Z., Yi, L., and Hang, C. 2018. Combining Fractional Order 563 Derivative and Spectral Variable Selection for Organic Matter Estimation of Homogeneous Soil Samples by VIS 564 NIR Spectroscopy. Remote Sensing 10:479.

$565 \mathrm{Hu}, \mathrm{Y}$., and Wang, X. 2017. Application of surrogate parameters in characteristic UV - vis absorption bands for 566 rapid analysis of water contaminants. Sensors and Actuators B: Chemical 239:718-726. 10.1016/j.snb.2016.08.072

567 Hughes, G. 1968. On the mean accuracy of statistical pattern recognizers. Information Theory IEEE Transactions on 568 14:55-63.

569 Isiyaka, H.A., Mustapha, A., Juahir, H., and Phil-Eze, P. 2018. Water quality modelling using artificial neural 570 network and multivariate statistical techniques.

571 Ju-Long, D. 1982. Control problem of grey systems. SYSTEMS \& CONTROL LETTERS 1:288-294.

Peer] reviewing PDF | (2019:07:39875:2:0:NEW 6 Nov 2019) 
572 Keller, S., Maier, P.M., Riese, F.M., Norra, S., Holbach, A., Boersig, N., Wilhelms, A., Moldaenke, C., Zaake, A.,

573

574

575

576

577

578

579

580

581

582

583

584

585

586

587

588

589

590

591

592

593

594

595

596

597

598

599

600

601

602

603

604

605

606

607

608

609

610

611 and Hinz, S. 2018. Hyperspectral Data and Machine Learning for Estimating CDOM, Chlorophyll a, Diatoms, Green Algae and Turbidity. International Journal of Environmental Research and Public Health 15. 10.3390/ijerph15091881

Kennard, R.W., and Stone, L.A. 1969. Computer Aided Design of Experiments. TECHNOMETRICS 11:137-148.

Lerch, R. 2015. Long-term agroecosystem research in the Central Mississippi River Basin: dissolved nitrogen and phosphorus transport in a high-runoff-potential watershed. JOURNAL OF ENVIRONMENTAL QUALITY 44:44.

Kotti, M., Zacharioudaki, D., Kokinou, E., and Stavroulakis, G. 2018. Characterization of water quality of Almiros river (Northeastern Crete, Greece): physicochemical parameters, polycyclic aromatic hydrocarbons and anionic detergents. Modeling Earth Systems and Environment 4:1285-1296. 10.1007/s40808-018-0504-3Li, C., Sun, L., Jia, J., Cai, Y., and Wang, X. 2016. Risk assessment of water pollution sources based on an integrated k -means clustering and set pair analysis method in the region of Shiyan, China. SCIENCE OF THE TOTAL ENVIRONMENT 557-558:307-316. 10.1016/j.scitotenv.2016.03.069

Morais, C.L.M., Santos, M.C.D., Lima, K.M.G., and Martin, F.L. 2019. Improving data splitting for classification applications in spectrochemical analyses employing a random-mutation Kennard-Stone algorithm approach. BIOINFORMATICS. 10.1093/bioinformatics/btz421

Oussama, A., Elabadi, F., Platikanov, S., Kzaiber, F., and Tauler, R. 2012. Detection of Olive Oil Adulteration Using FT-IR Spectroscopy and PLS with Variable Importance of Projection (VIP) Scores. JOURNAL OF THE AMERICAN OIL CHEMISTS SOCIETY 89:1807-1812.

Palmer, S.C.J., Kutser, T., and Hunter, P.D. 2015. Remote sensing of inland waters: Challenges, progress and future directions. REMOTE SENSING OF ENVIRONMENT 157:1-8.

Peerbhay, K.Y., Mutanga, O., and Ismail, R. 2013. Commercial tree species discrimination using airborne AISA Eagle hyperspectral imagery and partial least squares discriminant analysis (PLS-DA) in KwaZulu - Natal, South Africa. Isprs Journal of Photogrammetry \& Remote Sensing 79:19-28.

Peng J, Xu F, Deng K, and Wu J. 2018. Spectral difference of water quality different index concentrations: in langya mountain scenic area. Spectroscopy and Spectral Analysis 38:1499-1507(in Chinses).

Pu, H., Liu, D., Qu, J., and Sun, D. 2017. Applications of Imaging Spectrometry in Inland Water Quality Monitoring - a Review of Recent Developments. Water, Air, \& Soil Pollution 228. 10.1007/s11270-017-32948Rojas, F.S. 2009. Process Analytical Chemistry: Applications of Ultraviolet/Visible Spectrometry in Environmental Analysis: An Overview. APPLIED SPECTROSCOPY REVIEWS 44:245-265.

Rostom, N.G., Shalaby, A.A., Issa, Y.M., and Afifi, A.A. 2017. Evaluation of Mariut Lake water quality using Hyperspectral Remote Sensing and laboratory works. The Egyptian Journal of Remote Sensing and Space Science 20:S39-S48. 10.1016/j.ejrs.2016.11.002

Ryan, K., and Ali, K. 2016. Application of a partial least-squares regression model to retrieve chlorophyll-a concentrations in coastal waters using hyper-spectral data. Ocean Science Journal 51:209-221.

Shafique, N.A., Fulk, F., Autrey, B.C., and Flotemersch, J. 2003. Hyperspectral remote sensing of water quality parameters for large rivers in the Ohio River basin. Renard.

Song, K., Lin, L., Shuai, L., Tedesco, L., Duan, H., Li, Z., Shi, K., Jia, D., Ying, Z., and Shao, T. 2013. Using Partial Least Squares-Artificial Neural Network for Inversion of Inland Water Chlorophyll-a. IEEE Transactions on Geoscience \& Remote Sensing 52:1502-1517.

Peer] reviewing PDF | (2019:07:39875:2:0:NEW 6 Nov 2019) 
612 Verpoorter, C., Kutser, T., Seekell, D.A., and Tranvik, L.J. 2014. A global inventory of lakes based on high613 resolution satellite imagery. GEOPHYSICAL RESEARCH LETTERS 41:6396-6402. 10.1002/2014GL060641

614 Wang, H., Chen, Y., Zhang, Z., Chen, H., Li, X., Wang, M., and Chai, H. 2019. Quantitatively estimating main soil 615 water-soluble salt ions content based on Visible-near infrared wavelength selected using GC, SR and VIP. PeerJ 616 7:e6310. 10.7717/peerj.6310

617 Wang H, Zhang Z, Arnon K, Chen J, Han W. 2018. Hyperspectral estimation of desert soil organic matter content 618 based on gray correlation-ridge regression model. Transactions of the Chinese Society of Agricultural Engineering 619 34:124-131 (in Chinese)

620 Wang, J., Tiyip, T., Ding, J., Dong, Z., Wei, L., and Fei, W. 2017. Quantitative Estimation of Organic Matter 621 Content in Arid Soil Using Vis-NIR Spectroscopy Preprocessed by Fractional Derivative. Journal of Spectroscopy 622 2017:1-9.

623 Wang, L., Pu, H., and Sun, D. 2016. Estimation of chlorophyll-a concentration of different seasons in outdoor ponds 624 using hyperspectral imaging. TALANTA 147:422-429. 10.1016/j.talanta.2015.09.018

625 Wang Y., and Zhao Z. 2000. Comparison of two methods and applications for determination of indoor visible - near 626 infrared reflectance spectra of water. remote sensing information:2-5.(in Chinses)

627 Wang, Y., Jing, H., Yu, L., Su, H., and Luo, N. 2017. Set pair analysis for risk assessment of water inrush in karst 628 tunnels. Bulletin of Engineering Geology and the Environment 76:1199-1207. 10.1007/s10064-016-0918-y

629 Wang, Z., Sakuno, Y., Koike, K., and Ohara, S. 2018. Evaluation of Chlorophyll-a Estimation Approaches Using 630 Iterative Stepwise Elimination Partial Least Squares (ISE-PLS) Regression and Several Traditional Algorithms from 631 Field Hyperspectral Measurements in the Seto Inland Sea, Japan. SENSORS 18.

632 Williams, P. 2001. Implementation of near-infrared technology. Near-Infrared Technology in the Agricultural and 633 Food Industries.

634 Wold, H. 1966. Estimation of Principal Components and Related Models by Iterative Least Squares. Multivariate 635 Analysis 1:391-420.

636 Wu Y., Du S., and Yan Z. 2011. Ultraviolet spectral analysis method for the concentration detection of organic 637 pollutants in water bodies. Spectroscopy and Spectral Analysis 31:233-237(in Chinses).

638 Xiao, Z., Yi, L., and Hao, F. 2016. Modeling Soil Cation Concentration and Sodium Adsorption Ratio Using 639 Observed Diffuse Reflectance Spectra. CANADIAN JOURNAL OF SOIL SCIENCE 96:2012-2016.

640 Yang, Y.L., Yan, G.Y., and Lin, Q. 2004. Determination of heavy metal ions in Chinese herbal medicine by 641 microwave digestion and RP-HPLC with UV-Vis detection. MICROCHIMICA ACTA 144:297-302. 642 10.1007/s00604-003-0020-6

643 Zhang, M., Maoguo, G., and Yongqiang, C. 2018. Hyperspectral band selection based on multi-objective 644 optimization with high information and low redundancy. APPLIED SOFT COMPUTING:S1668392098.

645 Zhang, R., Wang, Y., Wang, K., Zhao, H., Xu, S., Mu, L., and Zhou, G. 2019. An evaluating model for smart 646 growth plan based on BP neural network and set pair analysis. JOURNAL OF CLEANER PRODUCTION 226:928647 939. 10.1016/j.jclepro.2019.03.053

648 Zhang, Y., Giardino, C., and Li, L. 2017. Water Optics and Water Colour Remote Sensing. Remote Sensing 9:818. $64910.3390 /$ rs 9080818

650 Zhu, T.T., Wu, L., Wang, X.L., Zhu, H., Zhu, X.C., Zhou, Q.G., Liu, X., and Cai, B.C. 2017. Investigation on 651 relationships between chemical spectrum and bioeffect of prepared rhubarb decoction in rats by UPLC-ESI-Q-TOF652 MS method coupled with gray correlation analysis. Journal of Functional Foods 31:104-112. 
653 Zhao, K., Xuan, A., 1996. Set pair theory-a new theory method of non-define and its applications. Syst. Eng. 14, 1865423 (in Chinese).

655 Zhou P, Yang W, Li M., Zheng L., and Chen Y.. 2017. Prediction of soil total nitrogen based on gray correlation 656 and extreme learning machine. Transactions of the Chinese Society for Agricultural Machinery 48:271-276(in 657 Chinses).

658 
Figure 1

spectral data curve

(A) Reflectance spectral curves (B) Standard normal variable reflectance curves.
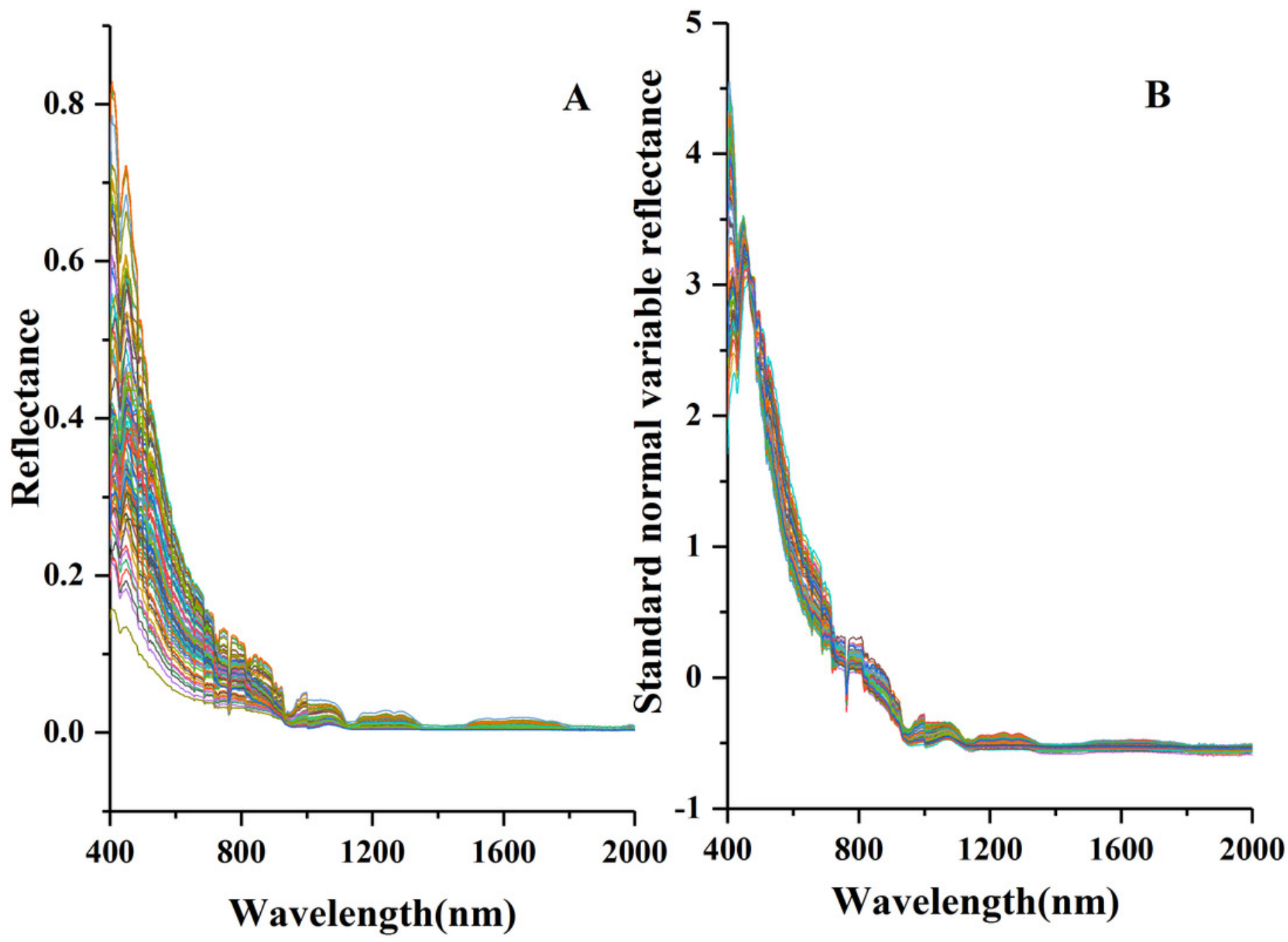
Figure 2

Correlation coefficients of water quality parameters with standard normal variable reflectance

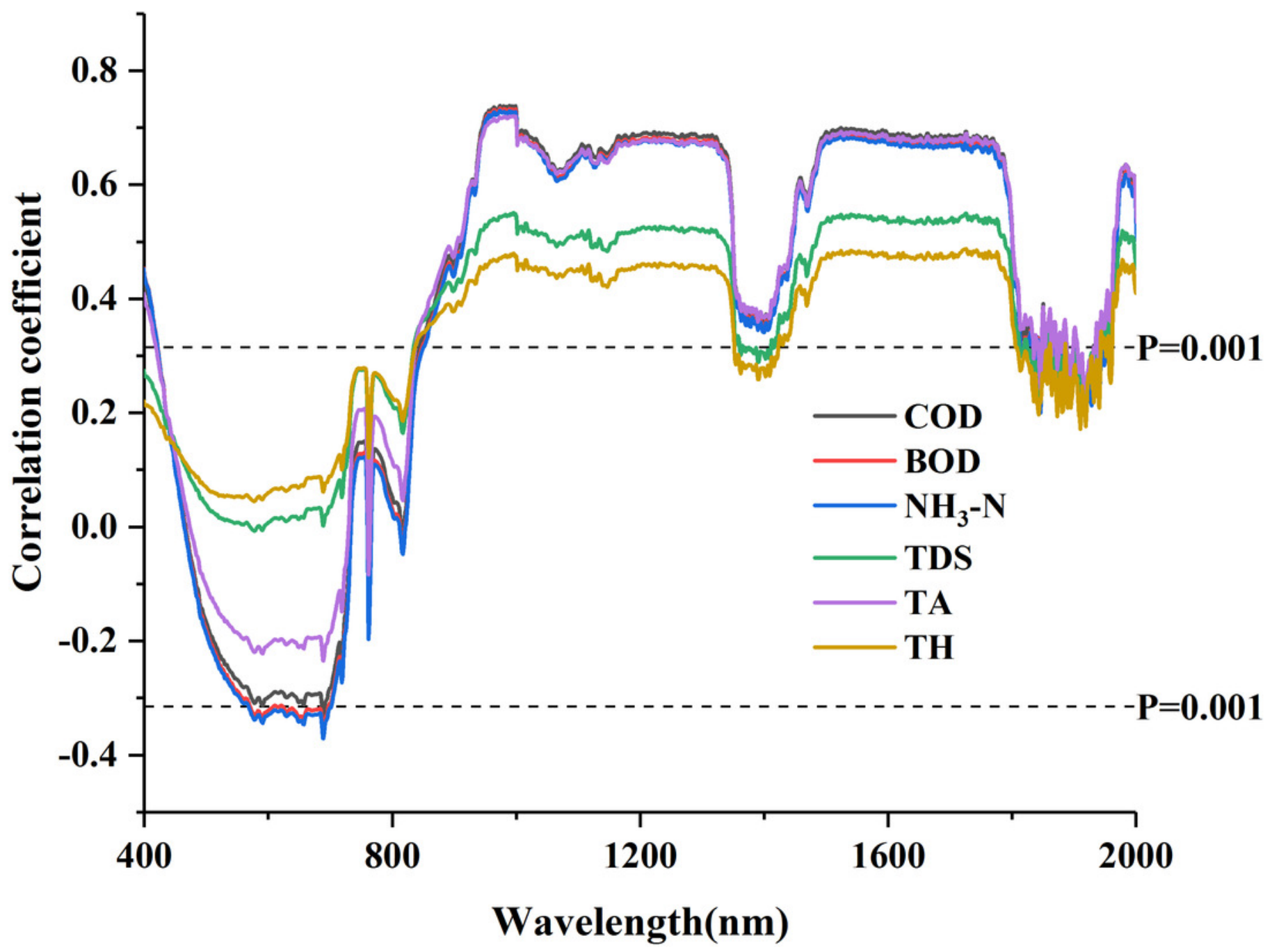


Figure 3

Gray correlation degree (GCD) for water quality parameters with standard normal variable reflectance

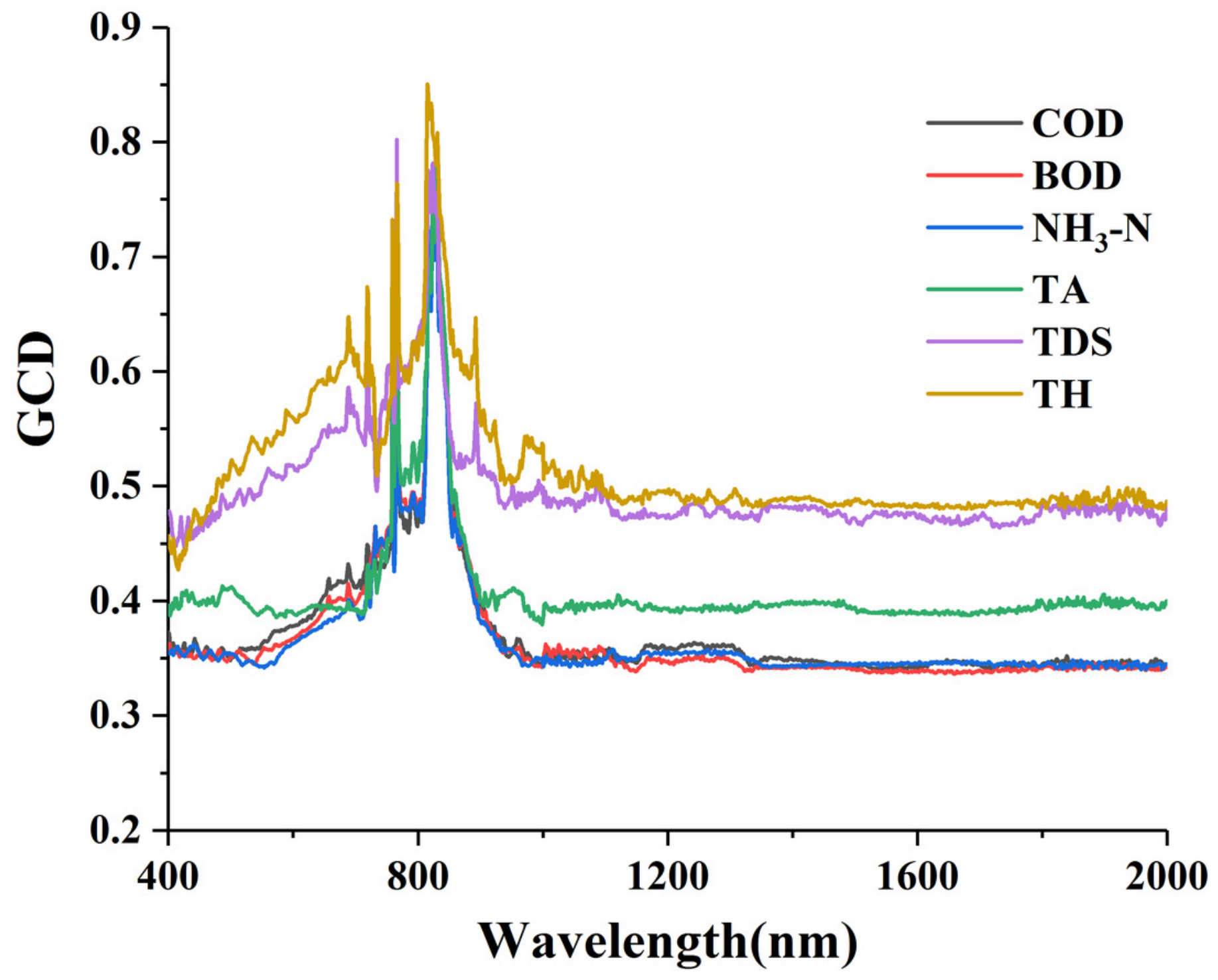


Figure 4

The VIP scores of water quality parameters with standard normal variable reflectance

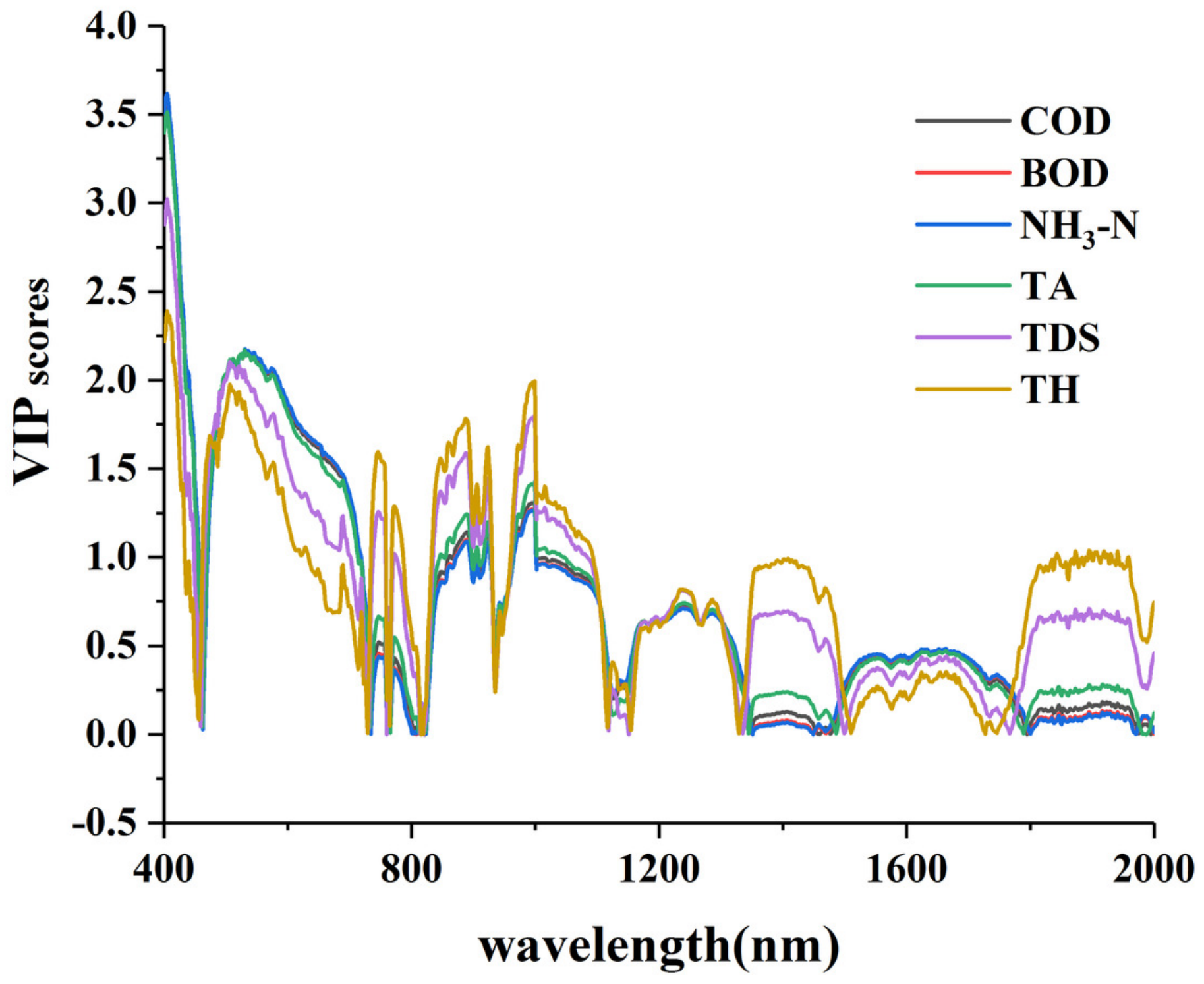


Figure 5

The SPA scores of water quality parameters with standard normal variable reflectance

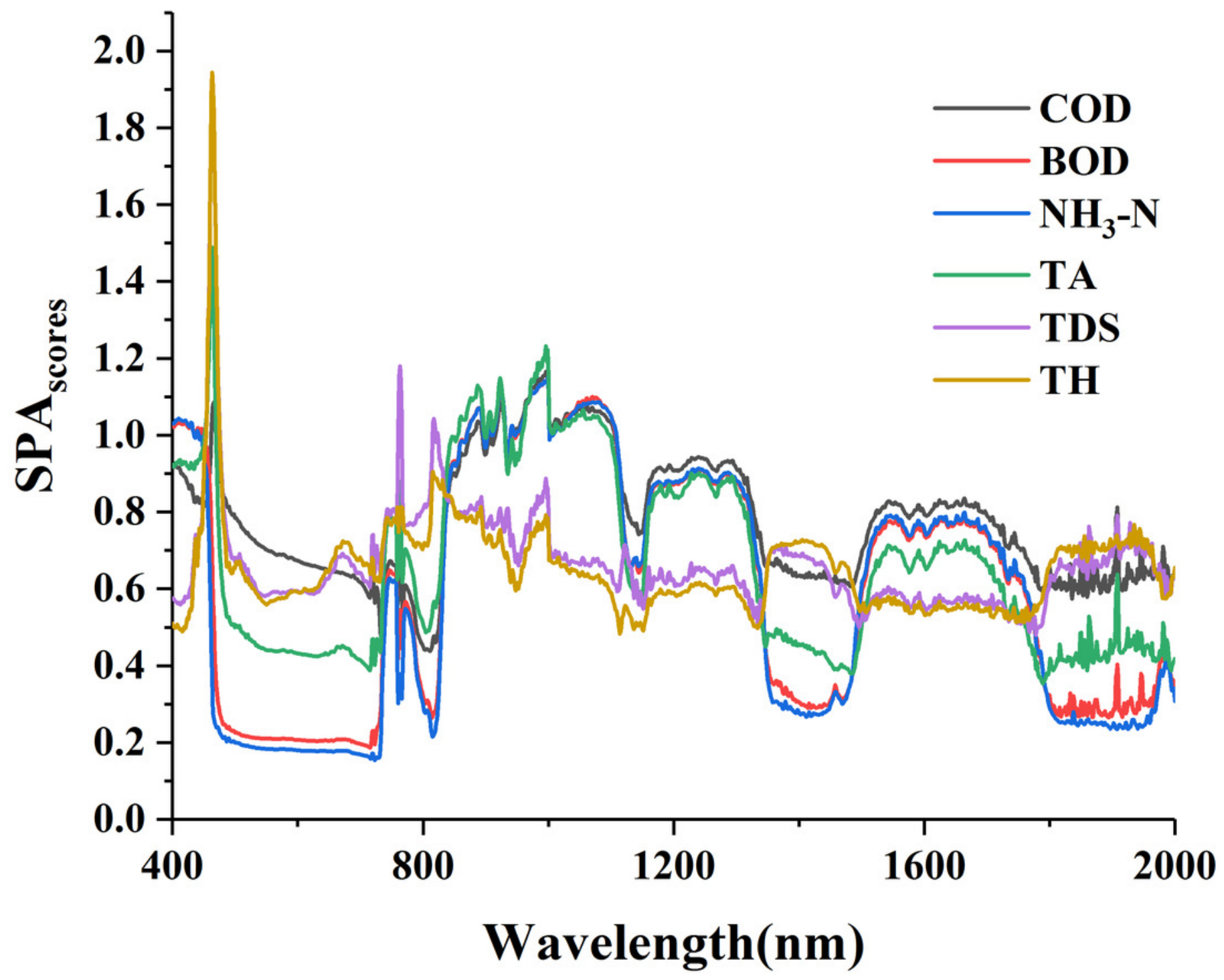


Figure 6

validation of water quality parameters based on the best model

(A) COD with GC-PLSR model (B) BOD with GC-ELM model (C) $\mathrm{NH}_{3}-\mathrm{N}$ with GC-ELM model (D) TDS with SPA-ELM model (E) TA with SPA-ELM model (F) TH with SPA-ELM model 

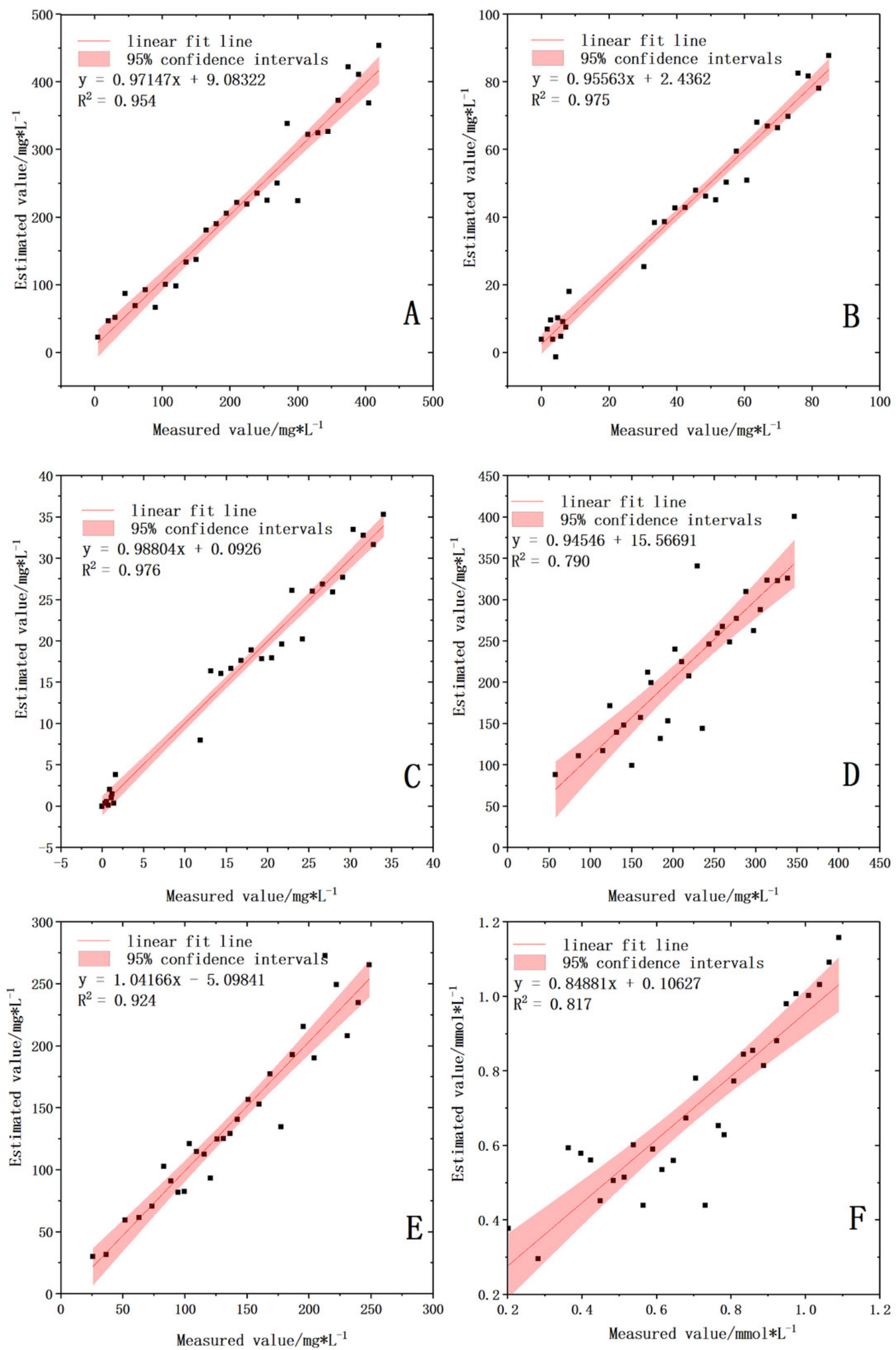


\section{Table $\mathbf{1}$ (on next page)}

Main water quality parameters 


\begin{tabular}{|c|c|c|c|c|c|c|}
\hline Parameters & $\begin{array}{l}\text { Water } \\
\text { inlet }\end{array}$ & $\begin{array}{c}\text { Anoxic } \\
\text { tank }\end{array}$ & $\begin{array}{c}\text { Aerobic } \\
\text { tank }\end{array}$ & $\begin{array}{l}\text { Sedimentation } \\
\text { tank }\end{array}$ & $\begin{array}{l}\text { Outlet of } \\
\text { water }\end{array}$ & Experiment methods \\
\hline $\mathrm{NH}_{3}-\mathrm{N} \quad(\mathrm{mg} / \mathrm{L})$ & 34.853 & 1.723 & 1.499 & 0 & 0 & $\begin{array}{l}\text { According to Nessler' } \mathrm{s} \text { reagent spectrophotometer } \\
\text { with the amount of visible light spectrophotometer } 722 \\
\mathrm{~N} \text { for determining } \mathrm{NH}_{3}-\mathrm{N}\end{array}$ \\
\hline $\begin{array}{l}\text { Total alkalinity } \\
\quad(\mathrm{mg} / \mathrm{L})\end{array}$ & 251.70 & 147.02 & 148.20 & 101.15 & 103.50 & According to acid base indicator titration method \\
\hline $\begin{array}{l}\text { Total hardness } \\
(\mathrm{mmol} / \mathrm{L})\end{array}$ & 1.09 & 1.13 & 1.13 & 1.17 & 1.11 & $\begin{array}{l}\text { According to the EDTA titration method (GB11914- } \\
\text { 1989) }\end{array}$ \\
\hline $\begin{array}{c}\text { Total dissolved } \\
\text { substance }(\mathrm{mg} / \mathrm{L})\end{array}$ & 351 & 323 & 317 & 344 & 343 & According to Gravimetric method (GB T5750.5-2006) \\
\hline $\mathrm{COD}(\mathrm{mg} / \mathrm{L})$ & 425 & 140 & 134 & 23 & 20 & $\begin{array}{l}\text { According to the dichromate method (GB11914-1989) } \\
\text { using a standard COD digestion apparatus(K-100) to } \\
\text { determine COD }\end{array}$ \\
\hline BOD $(\mathrm{mg} / \mathrm{L})$ & 86 & 8.5 & 13 & 3.1 & 6.2 & $\begin{array}{l}\text { According to the dilution and inoculation method } \\
\text { (HJ505-2009) with a constant temperature incubator } \\
\text { (HWS-150 type) for determining the content of BOD5 }\end{array}$ \\
\hline
\end{tabular}

1 


\section{Table 2 (on next page)}

Maximum gray correlation degree and band intervals of water quality parameters content with standard normal variable reflectance 


\begin{tabular}{cccc}
\hline Water quality parameters & Sensitive band numbers & Maximum GCD & Maximum GCD band intervals(nm) \\
\hline COD & 49 & 0.7949 & $820 \sim 830$ \\
BOD & 50 & 0.7974 & $820 \sim 830$ \\
$\mathrm{NH}_{3}-\mathrm{N}$ & 46 & 0.7973 & $820 \sim 830$ \\
TA & 93 & 0.7878 & $820 \sim 830$ \\
TDS & 381 & 0.802 & $815 \sim 825 / 766$ \\
TH & 601 & 0.8504 & $815 \sim 825$ \\
\hline
\end{tabular}

1 


\section{Table 3 (on next page)}

The maximum VIP scores of water quality parameters with standard normal variable reflectance 


\begin{tabular}{ccccc}
\hline Water quality parameters & $\begin{array}{c}\text { Sensitive band } \\
\text { numbers }\end{array}$ & $\begin{array}{c}\text { Maximum VIP } \\
\text { scores }\end{array}$ & $\begin{array}{c}\text { Maximum VIP band } \\
\text { interval(nm)1 }\end{array}$ & $\begin{array}{c}\text { Maximum VIP } \\
\text { band(nm) }\end{array}$ \\
\hline COD & 753 & 1.634 & $465 \sim 475$ & 766 \\
BOD & 770 & 1.439 & $464 \sim 474$ & 762 \\
$\mathrm{NH}_{3}$-N & 768 & 1.397 & $990 \sim 999$ & 999 \\
TA & 709 & 2.466 & $460 \sim 470$ & 464 \\
TDS & 497 & 4.275 & $460 \sim 470$ & 463 \\
TH & 543 & 4.893 & $460 \sim 470$ & 463 \\
\hline
\end{tabular}

1 
Table 4 (on next page)

The Set pair analysis (SPA) scores of water quality parameter with standard normal variable reflectance 


\begin{tabular}{ccccc}
\hline Water quality parameters & $\begin{array}{c}\text { Sensitive band } \\
\text { numbers }\end{array}$ & Maximum SPA & Maximum SPA band interval(nm) & $\begin{array}{c}\text { Maximum SPA } \\
\text { band(nm) }\end{array}$ \\
\hline COD & 750 & 1.598 & $465 \sim 475$ & 466 \\
BOD & 767 & 1.409 & $762 \sim 763$ & 762 \\
$\mathrm{NH}_{3}$-N & 765 & 1.364 & $990 \sim 999$ & 999 \\
TA & 696 & 2.409 & $460 \sim 470$ & 464 \\
TDS & 280 & 1.928 & $460 \sim 470$ & 463 \\
TH & 223 & 1.944 & $460 \sim 470$ & 463 \\
\hline
\end{tabular}

1 


\section{Table 5 (on next page)}

PLSR model results based on full band, GC, SPA and VIP screening band 


\begin{tabular}{|c|c|c|c|c|c|c|}
\hline \multirow{2}{*}{$\begin{array}{l}\text { Water quality } \\
\text { parameters }\end{array}$} & \multirow{2}{*}{$\begin{array}{c}\text { Wavelength } \\
\text { selection methods }\end{array}$} & \multirow{2}{*}{$\begin{array}{l}\text { Main factor } \\
\text { numbers }\end{array}$} & \multirow{2}{*}{$\frac{\text { Modeling set }}{\mathrm{R}^{2} \mathrm{C}}$} & \multirow{2}{*}{$\frac{\text { Validation set }}{\mathrm{R}^{2} \mathrm{p}}$} & \multirow{2}{*}{$\begin{array}{c}\text { Relative percent deviation } \\
\text { RPD }\end{array}$} & \multirow{2}{*}{$\begin{array}{r}\text { Robustness } \\
\text { Robus }\end{array}$} \\
\hline & & & & & & \\
\hline \multirow{4}{*}{ COD } & GC & 6 & 0.970 & 0.954 & 4.690 & 0.984 \\
\hline & VIP & 4 & 0.938 & 0.917 & 3.238 & 0.978 \\
\hline & SPA & 4 & 0.938 & 0.917 & 3.237 & 0.978 \\
\hline & All & 9 & 0.992 & 0.956 & 4.532 & 0.964 \\
\hline \multirow{4}{*}{ BOD } & GC & 5 & 0.976 & 0.965 & 5.335 & 0.988 \\
\hline & VIP & 10 & 0.992 & 0.951 & 4.424 & 0.958 \\
\hline & SPA & 4 & 0.958 & 0.930 & 3.348 & 0.971 \\
\hline & All & 7 & 0.990 & 0.960 & 4.998 & 0.970 \\
\hline \multirow{4}{*}{$\mathrm{NH}_{3}-\mathrm{N}$} & GC & 5 & 0.972 & 0.970 & 5.894 & 0.998 \\
\hline & VIP & 7 & 0.970 & 0.935 & 3.977 & 0.965 \\
\hline & SPA & 7 & 0.969 & 0.935 & 3.974 & 0.965 \\
\hline & All & 8 & 0.985 & 0.962 & 5.228 & 0.977 \\
\hline \multirow{4}{*}{ TDS } & GC & 8 & 0.876 & 0.772 & 2.049 & 0.880 \\
\hline & VIP & 3 & 0.767 & 0.758 & 1.892 & 0.988 \\
\hline & SPA & 5 & 0.820 & 0.793 & 2.150 & 0.964 \\
\hline & All & 5 & 0.862 & 0.791 & 2.126 & 0.918 \\
\hline \multirow{4}{*}{ TA } & GC & 5 & 0.917 & 0.890 & 2.963 & 0.971 \\
\hline & VIP & 4 & 0.883 & 0.927 & 3.578 & 1.049 \\
\hline & SPA & 4 & 0.883 & 0.927 & 3.588 & 1.050 \\
\hline & All & 7 & 0.956 & 0.921 & 3.206 & 0.963 \\
\hline \multirow{4}{*}{$\mathrm{TH}$} & $\mathrm{GC}$ & 12 & 0.978 & 0.900 & 2.871 & 0.920 \\
\hline & VIP & 4 & 0.779 & 0.733 & 1.764 & 0.941 \\
\hline & SPA & 3 & 0.794 & 0.708 & 1.701 & 0.892 \\
\hline & All & 5 & 0.820 & 0.817 & 2.228 & 0.996 \\
\hline
\end{tabular}


Table 6(on next page)

ELM model results based on full band, GC, SPA and VIP screening band 


\begin{tabular}{|c|c|c|c|c|c|c|}
\hline \multirow{2}{*}{$\begin{array}{l}\text { Water quality } \\
\text { parameters }\end{array}$} & \multirow{2}{*}{$\begin{array}{c}\text { Wavelength } \\
\text { selection methods }\end{array}$} & \multirow{2}{*}{$\begin{array}{l}\text { Main factor } \\
\text { numbers }\end{array}$} & Modeling set & Validation set & Relative percent deviation & Robustness \\
\hline & & & $\mathrm{R}^{2}{ }_{\mathrm{c}}$ & $R_{p}^{2}$ & RPD & Robust \\
\hline \multirow{4}{*}{ COD } & GC & 6 & 0.970 & 0.954 & 4.690 & 0.984 \\
\hline & VIP & 4 & 0.938 & 0.917 & 3.238 & 0.978 \\
\hline & SPA & 4 & 0.938 & 0.917 & 3.237 & 0.978 \\
\hline & All & 9 & 0.992 & 0.956 & 4.532 & 0.964 \\
\hline \multirow{4}{*}{ BOD } & GC & 5 & 0.976 & 0.965 & 5.335 & 0.988 \\
\hline & VIP & 10 & 0.992 & 0.951 & 4.424 & 0.958 \\
\hline & SPA & 4 & 0.958 & 0.930 & 3.348 & 0.971 \\
\hline & All & 7 & 0.990 & 0.960 & 4.998 & 0.970 \\
\hline \multirow{4}{*}{$\mathrm{NH}_{3}-\mathrm{N}$} & GC & 5 & 0.972 & 0.970 & 5.894 & 0.998 \\
\hline & VIP & 7 & 0.970 & 0.935 & 3.977 & 0.965 \\
\hline & SPA & 7 & 0.969 & 0.935 & 3.974 & 0.965 \\
\hline & All & 8 & 0.985 & 0.962 & 5.228 & 0.977 \\
\hline \multirow{4}{*}{ TDS } & GC & 8 & 0.876 & 0.772 & 2.049 & 0.880 \\
\hline & VIP & 3 & 0.767 & 0.758 & 1.892 & 0.988 \\
\hline & SPA & 5 & 0.820 & 0.793 & 2.150 & 0.964 \\
\hline & All & 5 & 0.862 & 0.791 & 2.126 & 0.918 \\
\hline \multirow{4}{*}{ TA } & GC & 5 & 0.917 & 0.890 & 2.963 & 0.971 \\
\hline & VIP & 4 & 0.883 & 0.927 & 3.578 & 1.049 \\
\hline & SPA & 4 & 0.883 & 0.927 & 3.588 & 1.050 \\
\hline & All & 7 & 0.956 & 0.921 & 3.206 & 0.963 \\
\hline \multirow{4}{*}{$\mathrm{TH}$} & GC & 12 & 0.978 & 0.900 & 2.871 & 0.920 \\
\hline & VIP & 4 & 0.779 & 0.733 & 1.764 & 0.941 \\
\hline & SPA & 3 & 0.794 & 0.708 & 1.701 & 0.892 \\
\hline & All & 5 & 0.820 & 0.817 & 2.228 & 0.996 \\
\hline
\end{tabular}

